\title{
On Bicycles, Sharks and Universities: The Emergence of a Higher Education Space in Europe
}

\section{INTRODUCTION}

In this world, there are three creations whose continued existence and general well-being depend on their moving forward. The first is the bicycle; the second the shark; the third, the university. It takes a very great artiste indeed not to fall off when his bicycle stops. As you know, if the shark does not advance, he dies the painful shark-like equivalent of asphyxiation. And as we all know, the university has been moving forward for the best part of 700 years or more, the only institution in a form recognizable today to have survived history's vicissitudes - along with the Church, the law and the Parliament of the Isle of Man, if the American writer Clark Kerr is to be believed, and there is no reason why he should not. Ours is a remarkably adaptive institution and always the symbol at one and the same time of knowledge seated within the nation state, but also beyond it.

To those who are historically minded - and it is worth recalling that, even today, the patterns of organization, authority, titles and ceremonial dress all remind us that the university is the repository of the nation's historic memory - the university has always claimed to be part of a community of learning that transcends the limitations of the nation-state. But there have also been periods when, for one reason or another, the attention of the university has focused on its homeland and sometimes, though rarer by far, on its immediate region. The tension between what one American student of public administration has termed the 'cosmopolitans' as against the 'locals' is not just a pattern in academic careers and commitment to an institution; it is also inherent in the university itself. The difficulty, as in most things, is to strike a judicious balance between the two, though, as I shall argue somewhat later, there are forms of co-operation developing within Western Europe's higher education space which go far in squaring this otherwise impossible circle. Nor is this tension of historic interest alone. On the contrary, it lies at the heart of a protracted debate about theories of economic development and the place of the university in this process. As such, this tension is central to the role that the university ought to play in the nation's strategy for economic growth. Indeed, there are few periods in the recent history of the university in which the disparities that come of being part of what is often alluded to as the global economy and those where the economy is still struggling to assume the dimensions of a modern industrial economy within the framework of the nation-state are as great as they are today.

Before going into the corpus of the subject of Prospects of an Emerging Higher Education Space in Europe, let me do two things: first, clarify the concept of a 'higher education space' and, second, put it in the form of a geo-historical setting. In Union terminology, a space is an area in which a variety of similar activities take place in a complementary manner. By definition, therefore, the concept transcends that basic unit which has been responsible for the development of the public provision of education since the time the nations of Europe assumed that charge, which in Scotland formally dates from 1694 and in Denmark from 1812. Of course, by 'basic unit' I am alluding to the nation-state. The concept of a 'space' does not substitute for the nation-state. Indeed, those who have dwelt long and hard on the arcania in the Treaty of Maastricht will already have noted that education remains an area of prime responsibility of the nation. Yet, over the past seven years or so, the pace of development, most particularly at the level of higher education, has so quickened that it is not exaggerating to argue that we are in the process of witnessing the emergence of what may be termed a new configuration in the world of policymaking.

\section{SEVERAL PERSPECTIVES}

There are several perspectives from which one may pursue this line of thought. The first lies within the relatively narrow confines of the models of analysis which have been used to present the basic mechanism of decision-making in a national setting. It has to do with developments inside individual higher education systems in Western Europe. From this particular angle, it may be seen as part of the forces that are amplifying the move towards a higher education space though they are not, in the first instance, a response to it. These developments have to do with the accelerating thrust towards decentralizing government on the one hand, and the process of devolution of certain aspects of policy-making in higher education on the other. Though there are exceptions to this general rule and, with traditional perversity, the United Kingdom is the best counter-example of a reinforcement in central government control over higher education, ${ }^{1}$ the move towards delegating downwards is very widespread, though the forms it assumes are often of bewildering variety. Here it is best to draw a line between those countries where delegation of responsibility involves strengthening the capacity for strategic development at the institutional 
level, and those where what is involved is a strengthening of the powers of oversight exercised by regional administrations. Strengthening of institutional initiatives in the areas of planning and internal resource allocation are part of current policy development in the Netherlands, ${ }^{2}$ Norway, Sweden. ${ }^{3}$ To be sure, this process involves a considerable cutting back on the often close control exercised by central Ministry; and from this perspective it may be said to confer a higher degree of institutional self-decision-making.

The second pattern places less emphasis upon institutional self-management than upon increasing the powers of regional bodies to co-ordinate and to shape individual establishments. It is a policy which emerges with greatest clarity in Spain ${ }^{4}$ and, more recently, in France. ${ }^{5}$ In essence, it confers upon regional authorities an additional role of co-ordinating the institutional response to regional needs through the capacity of regional authorities to allocate budgets over and above those granted by central government. In the case of Spain, these regions have a cultural designation and are, in addition, seen as a means of upholding regional identity as well as serving regional priorities in the more technical fields of qualifications, manpower supply and research contracting, etc.

These developments have obvious implications, not simply by creating a new and powerful force which may influence the way sectors of higher education evolve. By the same token, they also involve a shift in the distribution of power between the various strata involved in coordinating higher education. In what the American sociologist Burton Clark termed the 'Continental European' model of higher education co-ordination, the regional layer - with the exception of the Federal Republic of Germany where the Länder have cultural sovereignty and thus by extension are the prime co-ordinating forces - was scarcely visible to the naked eye. To say that it was weak is charity unbounded. In university affairs, the region was a non-entity. As I have suggested in the first of these two patterns of devolving responsibility - which reinforced institutional management - no major revision is required to the existing model. Devolution strengthens the institution, though whether it also strengthens the base units as against the increased power of central co-ordination via the administration will depend, as any cautious lawyer will put it, on cases and circumstances.

Decentralization, however, bids fair to modify one model by placing an intermediary stratum between national government and institutional leadership. Moreover, this additional stratum is far from being weak. There is evidence from both Spain and France of its increasing intervention to shape institutional priorities through its own, supplementary funding process. ${ }^{6}$ Moreover, in the case of Spain, in addition to the creation of regional Education Departments, the creation within universities of a so-called 'Social Council' - a species of giant Board of Trustees representing the major social partners and other external interests - has given rise to more than simply a powerful middle layer. The process of giving new expression to 'regional autonomy' has also brought about, on top of the formal bodies of internal academic coordination, a counter-balancing organism which, if anything, adds further weight to the interests of external society.

Arguably, this shift in the balance of powers is simply a medium-term swing of the pendulum and illustrates very properly the biological analogy I mentioned above - namely, that higher education can never truly stay still. It coincides, however, with another move which is taking place, this time beyond the level of the nation-state. This move may symbolically be represented by the various programmes conceived, developed and financed by the members of the European Union. Though targeted to specific groups - to students, staff and also practitioners in the various technological fields in the case of the COMETT programme; to students mainly at undergraduate level, though by no means exclusively so in the case of the ERASMUS programme; and towards young people not enrolled in higher education in the Youth for Europe Scheme - these programmes have one overriding objective. That objective may be variously couched in terms of changing the mentality of the younger generation, and setting in place a spirit of mobility and preparedness to seek one's fortune, and also one's training, in the range of establishments and facilities across the extent of the EU. But there are other interpretations as well which accompany the emergence of a higher education space in Europe. The encouragement of cross-frontier student flows, even though it may be seen as responding to a heart-felt demand among students, is nevertheless a policy and the programmes which set out to encourage it are, by the same token, instruments of policy. Seen from this particular angle, the development of the Union programmes of mobilization stands as a major revision to most of the models of higher education policy-making to the extent that they constitute a policy layer over and above that which has hitherto been the highest level of policy formulation, ie that of the individual Member State. Put prosaically, in place of the three layers of decision-making - central government, regional and institutional - which Clark's classic study identified, ${ }^{7}$ or the four which Becher and $\mathrm{Kogan}^{8}$ set out, we now have an additional one. It remains to be seen whether this new layer will act as a further instance of centralization or of top-down interventionism beyond the nation-state. It remains a moot point too, as regards that issue which is of particular concern to higher education analysts at present ${ }^{9}$ - namely, whether its effect will be to: shift the triangle of coordination which splits decision-making between state bureaucracy, academic oligarchy and 'the market'; amplify trends towards more 'market-based' co-ordination; or, on the contrary, serve to reinforce co-ordination by a centralized bureaucracy at the very time when it appears on the wane at the nation-state level.

The sceptic will point out, however, that these are concerns of a minor order, aspects which might fascinate the expert and the erudite. They have relatively little concern for the 'consumer', whether that consumer is the individual student or the individual establishment of higher 
education. Rather more important are surely the immediate implications and opportunities that arise from them for the individual. There is more than a grain of truth in this observation. Against it, however, one may pose the basic argument that subtends any political order which is based on a concept of democracy - namely, that no domain outside national security ought be excluded from public debate. And if accountability is fine for higher education, it is no less a fine thing for supra-governmental bodies. There is, as recent events in Denmark and France have pointed out, a high degree of risk in excluding certain issues from public concern. It is no less a high-risk venture to construct a European higher education space around short-term pragmatism, while resolutely refusing to tackle some of the long-term implications that are overridden by decisions taken in the short term.

The recreation of the 'mobile student' has profound implications for those processes of certification and qualification which, because they are the core of school and higher education systems, are also the core activities of the educating nation. Whatever the particular technical form these processes have assumed in the past - whether written or oral, whether limited to a small number of subjects or encyclopedic in their extent, whether administered by the state or by combinations of universities and schools - certification and thus access to higher education has remained bounded within the nation-state. Students who passed their maturité in Belgium usually moved on to attend Belgian establishments of higher education. The form, as well as the structure and duration of undergraduate degrees, were grounded upon the type of knowledge and pedagogy developed, tested and required in upper secondary schooling. There was, in short, a vertical continuity between secondary and higher education.

The development of a higher education space involves, of course, a degree of convergence in the conditions of access to higher learning across different countries; but this is more a matter of convergence between duration and structures of studies across Member States at the higher education level than it is at the level of secondary schooling. Certainly, the problem of access may partially be solved by stating that any student qualified for higher education in one Member State is eligible for access to higher education in another. But this is, at best, only a stopgap measure. It in no way solves the basic fact that convergence around a three-year duration of undergraduate studies, a development put in place in Spain and in Denmark with the United Kingdom now looking towards a two-year first degree, and around the principle of modularization of undergraduate studies, is at the same time a loosening of the links between what is taught in secondary school and what is being put in place in higher education. However difficult it is to identify, to operationalize, let alone to measure 'national pedagogic' styles and methods of teaching, they do exist and are powerful for the very fact that they form one of the major elements taken for granted in any school system. Simply to dismiss them in the name of greater mobility among a minority is, to say the least, to misunderstand the art of teaching and the part of national culture in it.

Even so, the opportunity to study elsewhere, to build up one's profile of skills across different systems of higher education, is a major break from the tradition whereby in Europe this was available to only a small élite. The internationalization of certification, of qualification and, thus, eventually, of insertion into a labour market, itself international, is a development without precedent since the nation-state assumed the responsibility for educating its citizens. This is particularly marked when one bears in mind that if the university is universal, the cultures it upholds and studies, even in a European setting, are equally diverse and no less particular.

Yet here we come across, as so often in the history of higher education, a strange paradox. For, if the concept of Europe as a higher education space reinforces the universality of the mission of higher education, it also redefines the place of nation-state higher education systems. Not all higher education systems, let alone individual establishments, have the same profile, standing and expertise. There are indeed certain fields which, if largely absent in one system, stand as a point of excellence in others; and, from another standpoint, that of systems adjustment, what is perceived as innovative or experimental in one may just as well be the veriest routine in its neighbour.

The creation of a higher education space in effect underlines the complementarity of one system of higher education vis-à-vis its neighbours at two levels. The first level is that of the individual consumer for whom in practice the way is now open to seek the highest level of excellence in teaching or in facilities which are no longer confined to his or her own state of origin. The second level is that of knowledge flows between systems, whether they have to do with the fundamental blocks of knowledge and their various combinations - the academic disciplines - or whether they have to do with techniques of management and administration at national or at institutional level. In other words, the development of a higher education space ought to increase the ability of higher education to learn from the example and from the good practice of its fellows elsewhere.

All pointers are indicating that this is indeed taking place. The spectacular rise in student numbers studying for a minimum of seven months in an establishment other than their home base is one example. Current figures are around 40,000 per year for ERASMUS students alone. And the impact on individual establishments of higher education is no less spectacular: of the 3500 institutions of higher education in the 12 Member States, some 1200 were in 1992 engaged in some 1900 inter-university co-operation programmes within the general framework of the ERASMUS programme, the Union's major student and staff exchange instrument. Nor is ERASMUS limited to the 12 EC Member States. Special arrangements exist for exchange between the EFTA countries such as Sweden, Austria and Switzerland together with the 
possibility of participation by the United States, though naturally these countries are expected to meet their own costs.

There are many ways of assessing the impact these and other mobility programmes have had in terms of student satisfaction and improvements in career opportunities, but there are two aspects which I wish to focus upon in particular. These are the importance such mobilizing programmes have upon the organization of international exchange at establishment level on the one hand, and the implications they have both for intra- as well as inter-regional co-operation on the other.

At a broad level of generalization, the development of a higher education space in Western Europe - and we do well not to forget that it also extends through the Trans-European Mobility Programme for University Studies (TEMPUS) to Central and Eastern Europe - may be seen, in addition, as part of that wider process of strengthening the role of individual establishments in the area of transnational co-operation. To be sure, what the powers of international relations offices are, to whom they report, whether they are viewed as a service function to academia or whether they view themselves as having a co-ordinative role over and above academia are important issues. It is a matter of fact that only in the past five to seven years have Europe's universities begun formally to organize their international relations, mainly under the prodding of the opportunities provided by Union mobility and collaborative research programmes. Hitherto this function, if not vestigial at the institutional level, has been run out of central government agencies. In other words, one of the effects of a nascent higher education space has been precisely to bring permanently on to the agenda of higher education establishments the issue of co-operation, be it transfrontier, cross-national or, as in the case of our host university, international co-operation.

Co-operation is, then, not merely the watchword, it is also the instrument for constructing and for advancing this higher education space. It is seen as a means of removing administrative and legal barriers between systems, as well as removing many of the barriers which have grown up as a result of the individual diversities of the history of nations within which higher education is set and which it was intended to preserve. But these are internal barriers within a Union which, as yet, has in the minds of many of its citizens still to go beyond the realities and conveniences of trade. What about the external barriers, which for many outside the Union may sometimes appear as constituting not a new identity but a new exclusivism?

\section{A BROADER BACKGROUND}

The emergence of a higher education space in Western Europe has to be set against a rather broader background. That background is one of shifting trade routes in student exchange on the one hand, and, on the other, what can only be described as a marginalization of many developing countries' universities from the international exchange of knowledge and students as they concentrate not on their development but on their survival.

The lesson we ought to retain from the emerging higher education space in Western Europe, however, is that the optimal use of human resources can only be realized through co-operation between nations and their systems of higher education. It is this vision which lies at the heart of what, without exaggeration, can be seen as the most important construction of Europe's economy since the end of the Second World War, and one in which higher education is a central and vital component. The temptation exists, and with the onset of recession it looms greater than ever, not merely to concentrate on developing our own strength, but to be rather more concerned with our own fate than with those whose fate is not only less enviable than ours, but who lie - to use the obvious metaphor - in the outer space of developing, or recently submerged, economies.

If, as I said at the outset, the continued existence of our universities depends on their moving forward and the Western European higher education space is emblematic of that progress, that gives us no licence to behave like the shark and to profit from the misfortune of others.

Guy Neave

\section{NOTES}

1. Walford, Geoffrey (1991) The United Kingdom, in Guy Neave and Frans van Vught, Eds., Prometheus Bound: The Changing Relationship Between Government and Higher Education in Western Europe, Oxford; Pergamon Press.

2. van Vught, Frans (1989) Governmental Strategies and Innovation in Higher Education, London; Jessica Kingsley.

3. Fürstenbach, John (1992) Why Pyramids Crumble, Higher Education Policy, 5, 3, 55-8.

4. Consejo de Universidades (1988) La Reforma Universitaria Española: Evaluación, e Informe, Madrid; Consejo de Universidades.

5. Prinborgne, Claude Durand (1990) Politique nationale? Politiques régionales: Les Contrats de Plan étatrégions, Savoir Education Formation, 1.

6. Guin, Jacques (1990) The Re-awakening of French Higher Education, European fournal of Education, 25, $2,123-46$.

7. Clark, Burton R. (1983) The Higher Education System: Academic Organization in Cross-National Perspective, Berkeley/Los Angeles; University of California Press.

8. Becher, Tony and Kogan, Maurice (1991) Process and Structure in Higher Education (2nd edn), London; Routledge.

9. On this, see: Neave, Guy and van Vught, Frans (1991) Prometheus Bound: The Changing Relationship Between Government and Higher Education in Western Europe, Oxford: Pergamon Press. 